\title{
INFORMATION SUPPORT FOR THE FINANCIAL ACTIVITy of Public Institutions
}

\author{
AlashKeVICH, M., Bobryakov, A., KlimenKO, A., \\ STEFANTSOV, A. \& SHCHERBAKOV, D.
}

Abstract: The efficiency of financial activities of public institutions depends considerably not only on the budgeting and management mechanisms they use, but also on the quality of their information support. The provision of comprehensive information support for the budget process involves the solution of a number of interconnected methodological and technical tasks. The article examines the structure and rules of the management of software and hardware providing information support for the financing of a network of educational institutions subordinate to the Ministry of Education and Science of the Russian Federation.

Key words: public institutions, financial activity, economic activity, information support, information analysis system
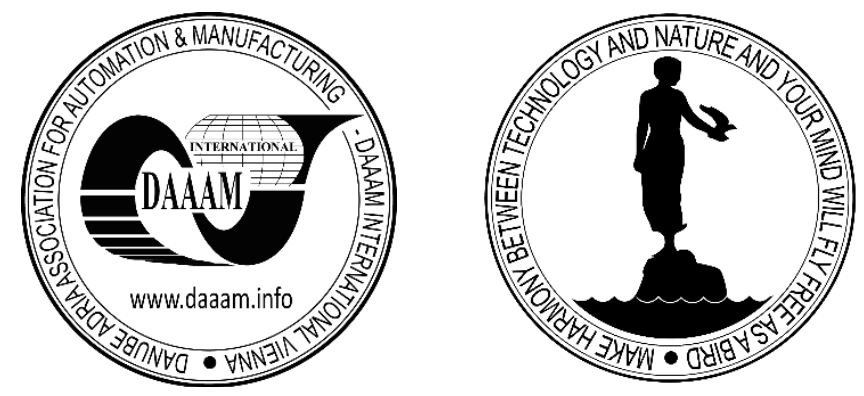

Authors' data: Director of Financial Department Alashkevich, M[ikhail]*; D.Sc. (Eng.) Head of Department Bobryakov, A[lexander]**; Univ.Prof. D.Sc. (Eng.) Klimenko, A[lexander]**; Ph.D. Stefantsov, A[lexey]**, Eng. Shcherbakov, $\mathrm{D}[\text { mitrii }]^{* *}$,

*Ministry of Education and Science of the Russian Federation, Tverskaya 11, Moscow, 125993, Russia; **National Research University "Moscow Power Engineering Institute", Krasnokazarmennaya 14, Moscow, 111250, Russia, alashkevich-my@mon.gov.ru, BobriakovAV@mpei.ru, KlimenkoAV@mpei.ru, StefantsovAG@mpei.ru, sche01@yandex.ru.

This Publication has to be referred as: Alashkevich, M[ikhail]; Bobryakov, A[lexander]; Klimenko, A[lexander]; Stefantsov, A[leksei] \& Shcherbakov, D[mitrii] (2016). Information Support for the Financial Activity of Public Institutions, Chapter 32 in DAAAM International Scientific Book 2016, pp.351-360, B. Katalinic (Ed.), Published by DAAAM International, ISBN 978-3-902734-09-9, ISSN 1726-9687, Vienna, Austria

DOI: $10.2507 /$ daaam.scibook.2016.32 


\section{Introduction}

The efficiency of economic activities of Russian budgetary institutions depends primarily on the methods they use and their economic mechanisms of planning and budgeting. The use of a new funding methodology for public institutions (PI), implemented as part of the public sector reform, requires not only a reorganization of the departmental principles of financial management, but also significant changes in the methods and rules of organizing financial and economic activities (FEA) at the level of subordinate institutions. In recent years, the functions and tasks of the participants of the budgetary process have changed significantly, namely: the range and volume of processed information have expanded, and the necessity of applying modern methods and means to support decision-making at all departmental management levels has sharply risen.

These changes require the automation and information support of the main stages of the budget process by means of the development and implementation of each department funded by the state budget of comprehensive information analysis systems (IAS). It is highly important to resolve the stated issues in large departments funded by the state budget, such as the Ministry of Education and Science of the Russian Federation. At present, the Ministry of Education and Science of Russia has developed and applies an integrated departmental suite of information analysis systems (Alashkevich et al., 2015) consisting of five main IAS and several related functional subsystems for the automation of separate areas of the budgeting process. It should be noted that these IS were developed several times by different software development companies using different technologies, technical platforms and software.

Using the suite has revealed the following major issues that decrease the work efficiency of employees of subordinate PIs (the IS end users) as they perform financing and budgeting operation functions:

- In their activity, the employees of public institutions have to work with several IS, each of which has its own user authentication system, interface, operation logics, and technical support. At the same time the integrated issues of technical support connected with the joint use of several IS have a low efficiency of being resolved due to the narrow specialization of existing user support services;

- The formation of answers to methodological questions (that the employees of public institutions have rather often due to the complexity and novelty of financing methodology reformation processes (Alashkevich et al., 2015) is not automated. These issues are solved mainly with the engagement of the responsible employees of the Ministry of Education and Science of Russia. It not only increases the labor effort of managing interactions (both on the part of the employees of public institutions and Ministry employees), but also increases the length of time to form and obtain answers.

The main focus areas on the resolution of detected problems and the improvement of budget financing quality include the development of the IAS department suite and formation of a departmental service of integrated information support (DSIIS) of the employees of public institutions that provides: 
- A single point of access to the IS in use implemented by integrating the information systems and services used to automate various areas of budgetary operations;

- A single point of access point to obtain methodological, technical and consultation support on issues of the financial and economic activities of subordinate institutions.

The solution to the task of providing a single point of access to the IS in use involves first and foremost including the software and hardware for the centralized maintenance of system reference manuals and registers used in integrated information systems into the structure of the departmental IAS integrated suite.

The article considers the operational structure and rules of software and hardware providing integrated information support (including methodological, technical and consultation support) of processes of the budgeting, financing and economic activities of the public institutions financed from the budget of the Ministry of Education and Science of Russia.

\section{The structure and objectives of comprehensive information support for the financial and economic activities of public institutions}

The departmental comprehensive information support of public institutions operates in accordance with the principle of a single point of contact and provides the employees of public institutions with methodological, technical and consultation support through various communication channels.

The main focuses of the integrated information support of financial activities of the public institutions are:

- Methodological and consultation support of the employees of public institutions on issues of efficient and effective management of the financial and economic activities of public institutions;

- The technical and consultation support of the employees of public institutions on issues of using information systems and services provided by the Department of Finance, Organization of the Budgetary Process, Methodology and Economics of the Ministry of Education and Science of the Russian Federation (hereinafter "Department") to automate the budgetary process;

- information support of the employees of public institutions, including news relating to important events in the activities of the Ministry of Education and Science of Russia and in regards to education, changes in the legal and regulatory base in the relevant area, methodological improvements, the best practices of financial and economic activities, etc.;

- Automation of the workflow between public institutions and the Ministry of Education and Science of Russia regarding financial and economic activities.

The authors put forth the functional structure of integrated information support that includes the following hierarchical levels:

- Level 0, which provides unauthorized access to departmental subject-oriented information including volumes of regulatory documentation, guidance materials and knowledge base in the relevant subject area. Using this level, the employees of 
Alashkevich, M.; Bobryakov, A.; Klimenko, A.; Stefantsov, A. \& Shcherbakov, D.....

public institutions can find answers to their methodological, technical, and informational questions on their own;

- Level 1, which formulates answers to the standard questions of the employees of public institutions. The answers are formed by experts at request reception centers using the special knowledge base;

- Level 2, which formulates answers to the standard difficult questions of the employees of public institutions. The answers are formed by experts working together in a geographically distributed network of subject-oriented competency centers;

- Level 3, which formulates answers to the most complex and difficult questions of the employees of public institutions, which require the making of managerial decisions. The answers are formed by the responsible employees of the Ministry of Education and Science of Russia.

The suggested structure allows to considerably cut the financial expenditures on the management and increase the efficiency and effectiveness of integrated information support functions thanks to the rational distribution of requests of the employees of public institutions among hierarchical levels depending on their complexity and difficulty.

The main tasks of integrated information support for the financial activity of public institutions resolved using this structure are:

- Provision of information support public institutions;

- Provision of unauthorized access to departmental subject-oriented information arrays of regulatory documentation, guidance materials and knowledge base;

- Provision of a single point of authorized entry for all participants of the budgetary process to departmental systems for collecting, storing and processing of planning and reporting economic information, as well as systems for automating these areas;

- The receipt of queries (generated via IP IE or telephone) by the departmental service of methodical, technical and advisory support, processing of the queries, and generation of high-quality, expert responses regarding methodological support by FEA of the public institutions and technical support for the use of information systems and services provided by the Ministry of Education and Science of Russia to such institutions;

- Automated generation of assignments for public institutions regarding the improvement of processes related to financial and economic activities, their performance monitoring, as well as quality control of the indicators of financial management in subordinate institutions;

- The provision of authorized access to departmental information arrays of statistical and analytical information on the main directions of FEA of the public institutions (arrays containing information consolidated from IS used by senior officials of the institutions and the Ministry of Education and Science of Russia in the decisionmaking process).

The article then examines the structures for the implementation of the main organizational elements and software/hardware providing the solution to the stated comprehensive information support issues suggested by the authors. 


\section{Implementation of elements of comprehensive information support in the economic activities of public institutions}

The departmental comprehensive information support of public institutions is a distributed, hierarchical, organizational and technical structure (Fig. 1.) that includes:

- A special e-portal for information exchange with subordinated institutions (hierarchy level 0), ensuring the provision of zero-level information services: the news feed; access to departmental information arrays of legal documents, guidance materials and the knowledge base; access to departmental information arrays of statistical and analytical information and services on processing such information and decision-making support; access to departmental information services of data collection and processing;

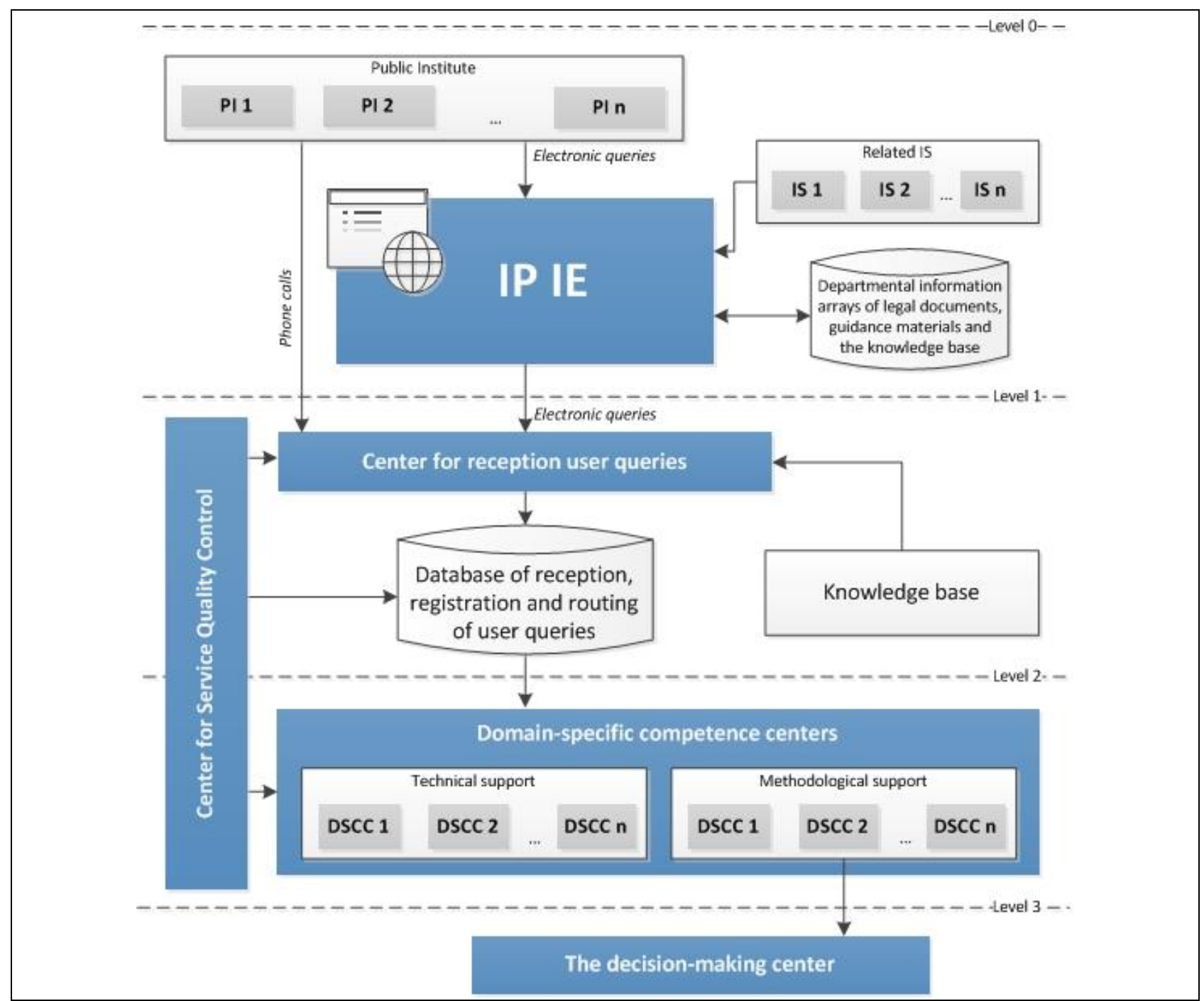

Fig. 1. Organizational and technical structure of the department of methodical, technical and advisory support for government agencies

- Center for reception, registration and routing of user queries (TsPRMO) (hierarchy level 1). The structure of the center includes:

○ Technical means for receiving queries generated via IP IE and/or received via telephone; 
Alashkevich, M.; Bobryakov, A.; Klimenko, A.; Stefantsov, A. \& Shcherbakov, D.....

- Software and hardware means of registration, cross-layer routing of queries and monitoring of the generation of responses to the queries;

- A knowledge base used to generate responses to queries on standard issues, containing formalized, verified, expert-certified answers to frequently asked questions;

- Domain-specific competence centers (DSCC), providing distributed expert processing of queries on non-standard issues (coming from hierarchy level 1) and generation of responses to such queries depending on the subject area (hierarchy level 2). The basic DSCC structure includes:

- Centers for methodological support in certain areas of economic activities of public institutions (as a rule, these are established at authorized universities that have successful experience and qualified experts in the relevant areas).

- Technical support centers for issues related to the use of information systems and services, provided by the Ministry of Education and Science of the Russian Federation (as a rule, these are established at organizations that develop the corresponding information systems);

- The decision-making center (hierarchy level 3), which provides expert processing of queries and generation of answers to the most difficult, non-standard questions that were not resolved at hierarchy level 2 (implemented with the involvement of senior officials of the Ministry of Education and Science of Russia).

- Center for Service Quality Control, providing quality control of advisory services related to technical and methodological support based on approved service standards (SLA) (Kearney \& Torelli, 2011).

The main organizational and labor principles of the departmental comprehensive information support are:

- All requests sent to the department of methodical, technical and advisory support via various communication channels enter the center for query reception, registration and routing and are registered in a database bearing the same name;

- TsPRMO generates a response to standard queries (with the use of a special knowledge base) and sends them to the user;

- Queries on non-standard issues are electronically routed to TsPRMO to the corresponding competence centers according to subject area. DSCCs generate a response to the queries received within the established timeframe. The response from DSCC is entered into the database of query registration and routing and is sent to the user;

- Responses to non-standard questions accumulated in the database of query registration and routing are periodically reviewed by experts, structured, classified into categories, and entered into the knowledge base;

- Monitoring of generation of responses to user queries is performed in accordance with the rules of service rendering. The monitoring is carried out using special software as per the following parameters: time required for individual steps of the process, qualitative characteristics of the process. 
A specialized e-portal of informational interaction with the public institution, ensuring provision of the above information services at level 0 , has a scalable distributed architecture (Fig. 2), developed with consideration of the specific infrastructure of the computing environment used, real opportunities for its development and modernization, user categories and qualification, and requirements to the quality of information involved in the processes of interaction (William et al., 1998). The portal architecture comprises:

- The representative level (FrontEnd), separating the hardware-software part of the server business logic and the applied IS from the user representation. The representative level forms the user interface and interacts with the integrating core of the portal. The level, navigation and search in the portal are based on modified solutions of Wordpress, a popular content management system;

- The integrating core (BackEnd), being a set of web-applications and server configuration scripts for processing user queries. The core provides interaction between portal users with the information systems and database servers being integrated. The core is implemented using the Java EE platform, SpringFramework and Struts frameworks, Hibernate OEM technology, Ant build tools, Eclipse development environments, and others. The core includes the following basic webapplications:

○ Organization of a single entry point and personal accounts of portal users, enabling unified authentication and user work in all the information systems and services;

- Maintenance of departmental subject-oriented databases and knowledge bases, providing automation of expert data processing procedures aimed at updating the stored guidance and expert information;

- User query registration, routing and processing, built based on OTRS (Opensource Ticket Request System) (OTRS Homepage). The interaction of the system with the representative level is provided by the API OTRS mechanism via a secure HTTPS protocol;

- Administration of the portal, providing solutions to tasks of user management and management of functional portal elements.

Currently, the portal integrates all the information systems used, as well as some new developments: IS for generating state assignments and implementation reports, IS on paid educational services. All the integrated IS can be accessed via personal accounts, which provide not only role user access to the full functionality of the IS used, but also enables personalization of the news feed, generation of assignments for institutions, and workflow automation.

The business logic of the portal makes use, directly (immediately referring to the database) or indirectly (via services provided by other departmental IS of the Department), of registers and information repositories of related subsystems, the most important of which is the Register of funded public institutions, addressed in detail below.

The solution to the task of combining the existing and new IAS into a single functionally and technologically integrated complex requires resources and mechanisms of centralized maintenance of system directories and registries used in 
Alashkevich, M.; Bobryakov, A.; Klimenko, A.; Stefantsov, A. \& Shcherbakov, D..... integrated information systems. The key element of the complex is the registry of statefunded public institutions, which includes basic information about the structure of the public institutions network, as well as extensive information on the details, characteristics and change history of the institutions. Maintenance (updating) of the register of state-funded public institutions is important due to partial changes in the subordination and organizational-legal forms of such institutions, resulting from structure optimization of the network under the jurisdiction implemented as part of public sector reform.

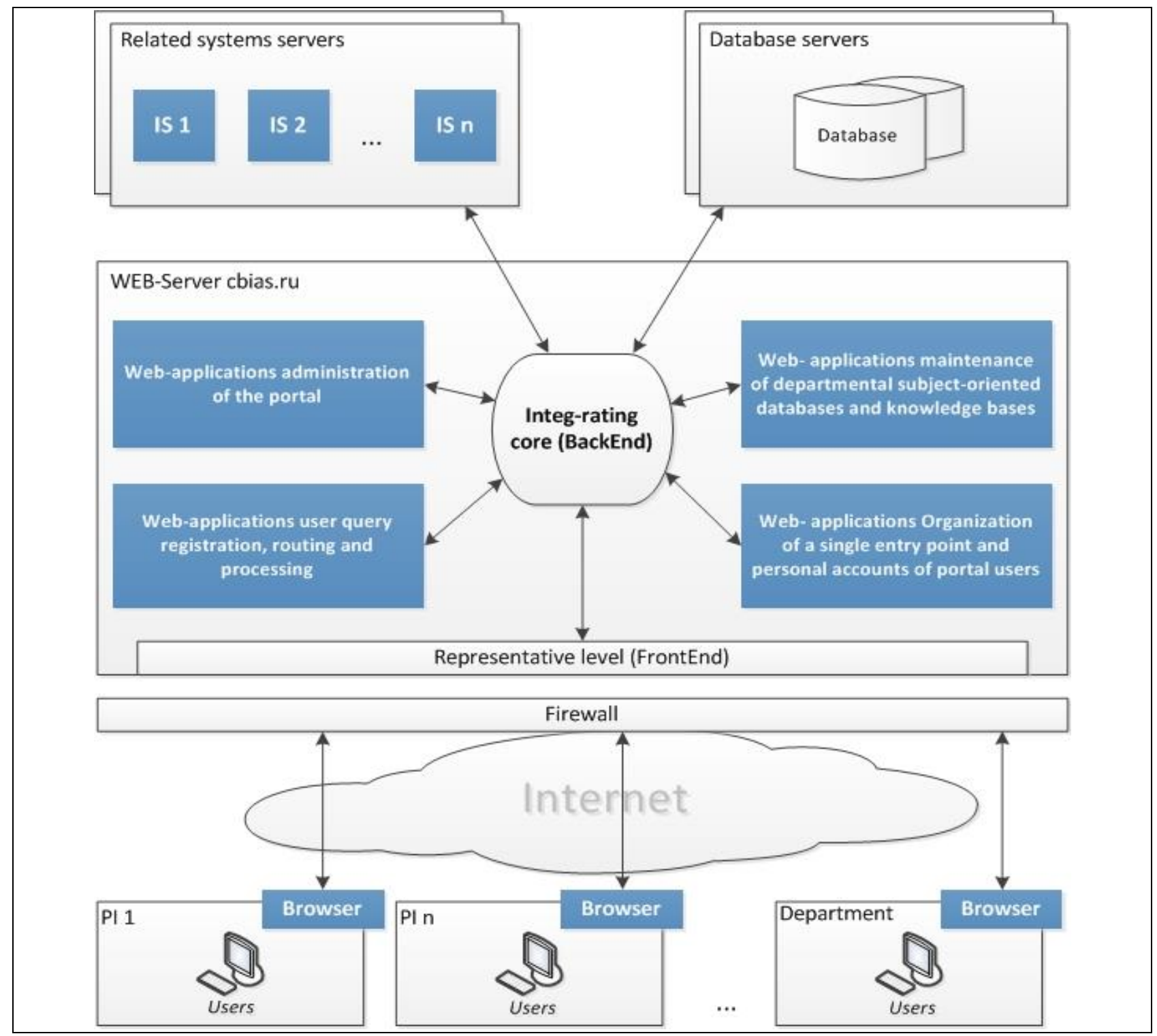

Fig. 2. Architecture of the special e-portal for informational interaction with public institutions

The scheme of interaction between the tools of maintaining the register of statefunded institutions performs the following core functions:

- Maintenance of the current list of funded public institutions, information on their reorganization;

- Maintenance of a core set of details of institutions (name, key codes in state information systems and classifiers, dates of updating); 
- Maintenance of a register with an expanded set of details of institutions (characteristics of institutions specific to their subject areas, such as bank accounts and personal accounts, research university status and other characteristics);

- Control of the relevancy and timeliness of the representation of changes in information on state-funded public institutions in state information systems;

- Provision of updated information on funded institutions to other IS of the Department.

Currently, the following algorithm is used to run the registry. The responsible employee of the Department monitors the departmental regulatory documentation (orders, instructions) that should result in changes in information on public institutions, and sets the status of the institution to "Update expected." For institutions with this status, surveys are regularly sent out to related and external state information systems in order to obtain updated information. Upon the receipt of the updated information, the new data and update date are recorded, and the updated information is provided to all the information systems of the Department.

The register of the funded public institutions provides informational interaction with the following IS groups:

- Public (external) information systems, which include the "Electronic Budget" integrated state information system (GIIS) and Uniform State Register of Legal Entities (USRLE);

- Related information systems of the Ministry of Education and Science of Russia: comprehensive automated system of the budget administration of the Ministry of Education and Science of Russia (CAS of BAM);

- Internal information systems of the Department: the Analytical Component of the Integrated Financial Management System of the Russian Ministry of Education and Science (AC IFMS), and others.

The main sources of factual information about the funded institutions are the state information systems (Chernyakova E., 2015), as well as the CAS of BAM. Interaction with these systems is carried out automatically, using open data processing mechanisms ("Electronic Budget" GIIS), asynchronous access to web services (USRLE, as well as internal interaction), and file sharing (CAS of BAM).

\section{Conclusions}

The insufficient efficiency of public institutions employees work in their performance of financing and budgeting operations is connected with how they must use multiple diversified IS and the complexity and considerable time spent on obtaining the necessary methodological support.

The stated negative aspects can be relieved by the development and implementation in the department of an integrated information support for the employees of public institutions and also by the modernization of the departmental IAS suite using the structural solutions suggested by the authors. 
Alashkevich, M.; Bobryakov, A.; Klimenko, A.; Stefantsov, A. \& Shcherbakov, D.....

The use of the results of this work for the Ministry of Education and Science of Russia will improve the quality of financing processes for subordinate institutions and the efficiency and effectiveness of the departmental IAS in use.

The management of operations of comprehensive information support for public institutions has ensured:

- Reduced time spent by employees of the economic services of institutions on retrieving necessary, up-to-date information checked by experts on methodological issues relating to the enhancement of FEA;

- Eenhanced efficiency and effectiveness of end-user information system and service operations provided by the Department thanks to the deep integration of systems within the information exchange portal.

Further areas for research include the following:

- Integration of the developed complex into the federal information environment used for preparing the electronic budget;

- distribution of developed solutions and the experience gained during their implementation to other federal executive bodies which have under their jurisdiction (in the subordinate structure) any institutions providing public services in the field of vocational training.

\section{Acknowledgments}

The authors wish to thank Employees of the Department of Finance, Organization of the Budgetary Process, Methodology and Economics of the Ministry of Education and Science of the Russian Federation, for methodological assistance in the formulation and solution of problems of information support of financial and economic activities of state institutions.

\section{References}

Alashkevich, M[ikhail]; Bobryakov, A[lexander]; Klimenko, A[lexander] \& Stefantsov, A[lexey] (2015). Automation and Informational Support of Budgetary Institution Financing Processes, Chapter 27 in DAAAM International Scientific Book 2015, pp.319-328, B. Katalinic (Ed.), Published by DAAAM International, ISBN 9783-902734-05-1, ISSN 1726-9687, Vienna, Austria DOI: 10.2507/daaam.scibook.2015.27.

Kearney, K.T.; Torelli, F. (2011). "The SLA Model". In Wieder, P.; Butler, J.M.; Theilmann, W.; Yahyapour, R. Service Level Agreements for Cloud Computing, Springer Science+Business Media, LLC. pp. 43-68. ISBN 9781461416142 William S. Davis, David C. Yen. The Information System Consultant's Handbook. Systems Analysis and Design. — CRC Press, 1998. — 800 c. — ISBN 0849370019. OTRS Homepage (https://www.otrs.com). Retrieved 25 November 2014. Chernyakova E. (2015) System "the Electronic budget" - a tool to ensure transparency, openness and accountability of activities in the field of public Finance management //Finance M. No. 8 (in Russian) 